\title{
Co-Encapsulated CpG Oligodeoxynucleotides and Ovalbumin in PLGA Microparticles; an in vitro and in vivo Study
}

\author{
Beatriz San Román ${ }^{1,2}$, Sara Gómez ${ }^{1}$, Juan M. Irache ${ }^{1}$, Socorro Espuelas ${ }^{1,3}$ \\ ${ }^{l}$ Department of Pharmacy and Pharmaceutical Technology, University of Navarra. Irunlarrea s/n, 31080 Pamplona, \\ Spain. ${ }^{2}$ Instituto de Agrobiotecnología (CSIC-UPNA-Gobierno de Navarra). Carretera de Mutilva s/n. 31192. \\ Pamplona, Spain. ${ }^{3}$ Institute of Tropical Health, University of Navarra. Irunlarrea s/n, 31080 Pamplona, Spain
}

Received June 12, 2014; Revised, November 17, 2014; Accepted, November 21, 2014, Published, December 2, 2014

\begin{abstract}
Purpose: The objective of this work was to evaluate the effect in the immune response produced by $\mathrm{CpG}$ oligodeoxynucleotides (ODN) co-encapsulated with the antigen ovalbumin (OVA) within poly(lactic-co-glycolic) acid (PLGA) 502 and 752 microparticles (MP). Methods: MP were prepared by blending 1,2-dioleoyl-3-trimethylammonium-propane (DOTAP) with PLGA and Total Recirculation One Machine System (TROMS) technology and contained OVA along with CpG sequences associated to DOTAP. After confirming the integrity of both encapsulated molecules, BALB/c mice were immunized with the resulting MP and OVA-specific antibodies and cytokine production were assessed in order to determine the immunological profile induced in mice. Results: One $\mu \mathrm{m}$ near non-charged MP coencapsulated very efficiently both OVA and CpG ODN. The release of both OVA and CpG was slow and incomplete irrespective of polymer. The results of the immune response induced in BALB/c mice indicated that, depending on the PLGA polymer used, co-encapsulation did not improve the immunogenicity of the antigen, compared either with the simply co-administration of both antigen and $\mathrm{CpG}$, or with the microencapsulated antigen. Thus, mice immunized with OVA associated to PLGA 756 displayed an IgG2a characterized response which was biased to an $\mathrm{IgG} 1$ profile in case of $\mathrm{CpG}$ co-encapsulation. On the contrary, the co-encapsulation of $\mathrm{CpG}$ with OVA into PLGA 502 significantly improved the isotype shifting in comparison with the one showed by mice immunized with OVA loaded PLGA 502. Conclusion: This study underlines the importance of MP characteristics to fully exploit simultaneous antigen and CpG ODN particulate delivery as effective vaccine construct.
\end{abstract}

This article is open to POST-PUBLICATION REVIEW. Registered readers (see "For Readers") may comment by clicking on ABSTRACT on the issue's contents page.

\section{INTRODUCTION}

Modern vaccine formulations are steering away from live attenuated viruses and bacterial toxoids to more defined and purified recombinant subunit proteins. However, these antigens are often poorly immunogenic due to lack of an innate immune stimulus and need an adjuvant to obtain an effective immune response. Poly(lactic-coglycolic) acid microparticles (PLGA MP) are promising vaccine adjuvants (1). The immunoadjuvant properties of particulates were classically ascribed to enhanced phagocytic uptake of encapsulated antigen by antigen presenting cells (APC) and more recently to NALP3 inflammasome activation (2). This mechanism of action is shared with other particulates as Alum or the emulsion MF59 ${ }^{\circledR}$, currently authorized for human vaccines (3).

Although the shaping of specific immune response by Nucleotide-binding oligomerization domain-Like Receptors (NLR) activation is not well-defined yet $(4,5)$, it seems that particulate adjuvants are less-effective in promoting Th1type immune responses than Toll-Like receptors (TLR) ligands such as i.e. $\mathrm{CpG}$ ODN (oligodeoxynucleotides) or monophosphoryl lipid A $(6,7)$. TLR agonists, discovered twenty years ago, showed great potential and extreme versatility as vaccine adjuvants (8). However, concerns about security and potential risk of autoimmune disorders have hindered their approval in licensed products $(9,10)$.

Therefore, the use of particles as carriers for both antigen and TLR agonists has been proposed as an "ideal" sub-cellular and well-defined vaccine model $(11,12)$.

Corresponding Author: Dra. Socorro Espuelas Millán Department of Pharmacy and Pharmaceutical Technology, Tropìcal Health Institute University of Navarra, Ap.177, 31080 Pamplona, Spain. E-mail: sespuelas@unav.es 
The combination of particulate formulation with TLR agonists can enhance vaccine efficacy because of the synergistic and simultaneous activation of TLR and NLR signalling pathways (13). Moreover, the particulate delivery can selectively target TLR agonists to APC, avoiding their rapid spread into the body and off-target toxic effects (14).

The clinical emplacement of MP as immunoadjuvants has still to overcome several drawbacks. Some of them, such as the entrapment the antigen within MP without loss of antigenicity, as well as the challenge of ensuring a consistent quality of the formulation, are been surmounted with new fabrication technologies. Therefore, there is a big hole in the knowledge of the influence of particles physicochemical characteristics as size $(15,16)$, composition, antigen release kinetic (17) and others (18) in the outcoming immune response. Furthermore, recent studies have evidenced the effect of particle size (19) and the strength of interaction of CpG ODN loaded particles $(20,21)$ in the immunestimulatory activities of particulate based vaccines co-delivering antigen and $\mathrm{CpG}$ ODN.

In this work, we evaluate the resulting immune response elicited by co-encapsulated CpG sequences and ovalbumin (OVA). The MP were prepared with two types of PLGA, 502 and 756 , very different in terms of molecular weight and hydrophilicity (22). The optimal $\mathrm{CpG}$ and OVA encapsulation was achieved by the assistance of the cationic lipid 1,2-dioleoyl-3trimethylammonium-propane (DOTAP) and our Total Recirculation One Machine System (TROMS) methodology. This approach was based on previous work that strengthened the necessity of incorporating positive molecules in MP composition (23) and the suitability of TROMS method to encapsulate compounds into MP with efficiency and without affecting their integrity (24).

\section{MATERIAL AND METHODS}

\section{Preparation of OVA and/or CpG MP}

MP were prepared using a $\mathrm{W}_{1} / \mathrm{O} / \mathrm{W}_{2}$ emulsion (water-in oil-in water) and solvent evaporation technique by TROMS $(23,24)$. Briefly, $50 \mathrm{mg}$ $(4 \% \mathrm{w} / \mathrm{v})$ of $12-\mathrm{KDa}$ PLGA $50: 50$ or $98-\mathrm{KDa}$ PLGA 75:25 (PLGA 502 and 756, respectively; Boehringer Ingelheim Gmbh, Germany) were dissolved in a solution of dichloromethane containing DOTAP $(1 \%$ w/w with respect to the polymer; Avanti Polar Lipids Inc, USA). This amount of DOTAP corresponds with a ratio N/P
1 , defining this parameter as the molar relation of amine groups in the cationic molecule, which represent the positive charges, to phosphoric groups in the oligonucleotide, which represent the negative charges. This solution was injected under a turbulent regime $(50 \mathrm{~mL} / \mathrm{min})$ onto the inner aqueous phase using a needle with a diameter of $0.17 \mathrm{~mm}$. This aqueous phase was composed by Pluronic ${ }^{\circledR}$ F68 $(250 \mu \mathrm{L}, 6 \%$ w/v) containing OVA (3 mg; Sigma-Aldrich, USA) and/or CpG sequences $(300$ nmol, \#1826, 5-3: tccatgacgttcctgacgtt; Coley Pharmaceutical Gmbh, Germany), depending on the formulation. Then, this $\mathrm{W}_{1} / \mathrm{O}$ emulsion was forced to circulate through the system $(2 \mathrm{~min})$ to homogenize the droplet size. After that, the first emulsion was injected onto a solution of PVA $(7.5 \mathrm{~mL}, 0.5 \%$ $\mathrm{w} / \mathrm{v})$ in the same conditions as the initial emulsion. This resulted in the formation of a double emulsion, which was further homogenized by circulation through the system for $4 \mathrm{~min}$. Afterwards, the $\mathrm{W}_{1} / \mathrm{O} / \mathrm{W}_{2}$ emulsion was stirred to evaporate the organic solvent and allow the formation of the MP. Later, MP were collected by centrifugation $(20 \mathrm{~min}, 27100 \times \mathrm{g})$ and washed twice with deionised water, and then lyophilized.

Empty MP were prepared in the same way as described above but without including either OVA or $\mathrm{CpG}$ sequences in the inner aqueous phase.

\section{Microparticle characterization}

MP size was determined by laser diffractometry using a particle size analyzer (Mastersizer S laser sizer, Malvern Instruments, UK) (23). The mean size was expressed as the volume mean diameter $(\mathrm{D}[4,3])$ in micrometers $(\mu \mathrm{m})$. The Sauter diameter $(D[3,2])$ was also determined and the polydispersity was expressed as the ratio of $\mathrm{D}[4,3] / \mathrm{D}[3,2]$. Zeta potential was assessed by laser Doppler velocimetry in a Zetasizer Nano ZS (Malvern Instruments, UK) (23). The measurements were carried out diluting the samples in distilled water at room temperature (RT). The yield of the preparation was expressed as the percentage (\%) of the initial amount of polymer which formed lyophilized MP. Besides, the shape and morphology of the MP were evaluated by scanning electron microscopy. Freeze-dried MP were mounted on double-faced adhesive tape on metal stubs, coated with gold to a thickness of $16 \mathrm{~nm}$ (Emitech K550; Quorum Technologies, UK) and further the observation was made by scanning electron microscopy (Zeiss DSM 940 A, Germany) with a digital imaging 
capture system (Point Electronic $\mathrm{GmBH}$, Germany).

The OVA content of MP was determined using the MicroBCA protein assay (Thermo Fisher Scientific, USA), following manufacturer`s instructions, as previously described (23). Briefly, freeze-dried MP were resuspended in $\mathrm{NaOH} 0.1$ $\mathrm{N}(5 \mathrm{mg} / \mathrm{mL})$ and maintained under magnetic stirring overnight at RT. The resulting suspension was centrifuged $(20 \mathrm{~min}, 27100 \times \mathrm{g})$ and the supernatant was incubated with the MicroBCA reagent for $2 \mathrm{~h}$ at $37^{\circ} \mathrm{C}$. The colorimetric reaction was measured in a spectrophotometer (iEMS Reader MF; Thermo Fisher Scientific, USA) at $562 \mathrm{~nm}$ and compared with the absorbance data obtained with non-encapsulated OVA. For this purpose, control calibration curves (1.5-50 $\mu \mathrm{g} / \mathrm{mL}$ ) were prepared using OVA dissolved in $\mathrm{NaOH} 0.1 \mathrm{~N}$.

CpG oligonucleotide containing MP were similarly incubated with $\mathrm{NaOH} 0.1 \mathrm{~N}$ overnight at RT. The amount of $\mathrm{CpG}$ sequences was estimated fluorimetrically (PerkinElmer LS 50B Luminiscence Spectrometer, USA) based on the fluorescence measured at $522 \mathrm{~nm}$ after the incubation of the samples for $10 \mathrm{~min}$ with Oligreen $^{\circledR}$ ssDNA Quantitation reagent (Invitrogen, USA), as recommended by the manufacturer's instructions. $\mathrm{CpG}$ oligonucleotide in solution was dissolved in TE buffer (Tris-HCl $200 \mathrm{mM}$, EDTA $20 \mathrm{mM}, \mathrm{pH}$ 7.5) and incubated with the fluorescent reagent to perform a sigmoidal-fitted calibration curve (0.05-1.5 $\mu \mathrm{g} / \mathrm{mL})(23)$.

The encapsulation of the OVA and $\mathrm{CpG}$ was expressed as the amount of molecule per milligram of MP. Besides, the entrapment efficiency was estimated as the ratio (\%) between the loaded and the initial quantity of OVA and $\mathrm{CpG}$ sequences added to the formulation, taking into account the yield of the fabrication of the MP.

\section{In vitro release study}

MP (5 mg) containing OVA and/or CpG oligonucleotide were suspended in phosphate buffered saline (PBS, $1 \mathrm{~mL}, \mathrm{pH}$ 7.4) in eppendorf tubes (25). The suspension was gently shaken under rotating agitation at $37^{\circ} \mathrm{C}$. At various time intervals, the supernatant was removed after centrifugation $(20 \mathrm{~min}, 27100 \times \mathrm{g})$ and replaced with fresh medium. In the supernatants, the amount of OVA and $\mathrm{CpG}$ sequences were determined as described above. Empty MP were used as controls and subjected to the same procedure. Release data were expressed as the cumulative percentage of the protein and the oligonucleotide released at each time in comparison with the content of these molecules in the MP versus the time.

\section{Structural integrity and antigenicity of the entrapped OVA}

The structure and the antigenicity of OVA was analysed after MP preparation and after its in vitro release using Coomassie Brilliant Blue stain and Western-blot. Briefly, OVA MP (5 mg) were suspended in dichloromethane overnight at $4{ }^{\circ} \mathrm{C}$. Then, the organic solvent was evaporated with nitrogen and the pellet was suspended in electrophoretic sample buffer (Tris-HCl $62.5 \mathrm{mM}$ $(\mathrm{pH}$ 6.8), $10 \%$ glycerol, 2\% SDS, 5\% $\beta$ mercaptoethanol and $0.05 \%$ bromophenol blue). Afterwards, the sample was centrifuged (10 min, $2300 \times \mathrm{g}$ ) to remove any polymeric residues and boiled during $10 \mathrm{~min}$ to separate possible OVA degraded fragments.

Samples were analysed by using $15 \%$ acrylamide gels with the discontinuous buffer system of Laemmli (26). Then, gels were stained with Coomasie Brilliant Blue R-250 (27) or subjected to Western-blot as described previously (28). Immunoglobulin $G$ against OVA from mouse (Nordic Immunology, Netherlands) was used as primary antibody whereas horseradish conjugated rabbit anti-IgG and 4-chloro, 1naphtol were used as secondary antibody and chromogen, respectively.

\section{Integrity of CpG sequences}

The integrity of $\mathrm{CpG}$ oligonucleotide loaded or released from the MP was evaluated by the determination of its melting temperature (29). On one hand, MP (5 mg) containing $\mathrm{CpG}$ sequences were degraded with $\mathrm{NaOH} 0.1 \mathrm{~N}$ under magnetic shaking overnight to extract the oligonucleotide. On the other hand, supernatants obtained after 38 days of incubation in PBS in the release studies were used directly to measure the integrity of the $\mathrm{CpG}$ released from the particles. Both solutions were adjusted to an optimal concentration of 4 $\mathrm{ng} / \mu \mathrm{L}$ and incubated with the sense oligonucleotide (5'-3`: AACGTCAGCAACGTCATGGA; Thermo Fisher Scientific, USA) in the presence of SYBR Green ${ }^{\circledR}$ I nucleic acid gel stain (Invitrogen, USA) diluted in buffer Tris- $\mathrm{HCl}$ $100 \mathrm{mM}$ (pH 8.9), $\mathrm{NaCl} 100 \mathrm{mM}$ and $\mathrm{MgCl}_{2} 14$ $\mathrm{mM}$. In this context, sense and antisense oligonucleotide tended to form a double strand, which enclosed the SYBR Green ${ }^{\circledR}$ I nucleic acid 
gel stain. This compound emits fluorescence when it is associated to the duplex and its signal is proportional to the hybridization capacity of the oligonucleotides. This parameter was measured in a fluorescence temperature cycler (Lightcycler, Roche Diagnostics $\mathrm{GmbH}$ ). Precisely, the duplex was heat at $0.2{ }^{\circ} \mathrm{C} / \mathrm{s}$ until $95{ }^{\circ} \mathrm{C}$ measuring the fluorescence signal during the process and obtaining a melting curve. For improved visualisation of the melting temperature or $\mathrm{T}_{\mathrm{m}}$ (temperature at which $50 \%$ of the oligonucleotide is forming a double strand) the initial data were derived to obtain melting peaks (fluorescence $(\mathrm{F})$ versus temperature ( $\mathrm{T}$ ) by plotting the negative derivative of fluorescence over temperature versus temperature; $(-\mathrm{dF} / \mathrm{dT})$ versus $\mathrm{T})$.

\section{Bone marrow-derived dendritic cells (BMDC) generation and activation}

C57BL/6 mice (8 weeks, female) were obtained from Harlan Interfauna Ibérica (Spain) and housed in pathogen-free conditions according to the guidelines of the Ethical Committee of the University of Navarre in line with the European legislation on animal experiments (86/609/EU). As previously described (30), femurs and tibia were extracted after animal cervical dislocation and the bone marrow was flushed out using a 26 gauge needle with supplemented RPMI 1640 medium $(0.1 \% \beta$-mercaptoethanol $50 \mathrm{mM}, 0.5 \%$ sodium pyruvate $100 \mathrm{mM}, 1 \mathrm{IU} / \mathrm{mL}$ penicillin, 1 $\mu \mathrm{g} / \mathrm{mL}$ streptomycin and $10 \% \mathrm{v} / \mathrm{v}$ foetal bovine serum; all from Invitrogen, USA). In the cell suspension, erythrocytes were lysed and lymphocytes and granulocytes were deplected by incubation with different antibodies against CD4, CD8, Ly-6G/Gr1 and CD45R and rabbit complement. The final suspension was grown at $1 \times 10^{6}$ cells $/ \mathrm{mL}$ in 6 -well plates $(2 \mathrm{~mL} /$ well $)$ with RPMI 1640 medium containing IL-4 and GMCSF (25 ng/mL; PrepoTech EC, USA). Once confirmed that the bone marrow-derived dendritic cells (BMDC) precursors were immature dendritic cells (DC; CD11c+ subset), two-thirds of the medium was replace with fresh medium containing GM-CSF and IL-4 at days 2, 4, 5 and 6 . The activation of BMDC was evaluated by IL12 production and up-regulation of surface maturation markers. After $18 \mathrm{~h}$ incubation with 2 $\mu \mathrm{g} / \mathrm{ml} \mathrm{CpG}$ associated to MP, supernatants were collected for IL-12 determination using a commercial ELISA kit. The cells were washed, pre-incubated with a rat antiCD16/CD32 mAb (2.4G2 clone) and stained with antiCD40-PE (3/23 clone) and anti-CD86-PE (GL1 clone) or appropriate isotype control antibodies and analysed by flow cytometry (FACs Calibur, BD). All antibodies and ELISA recombinant standard were from BD Pharmingen.

Untreated BMDC, free CpG $(2 \mu \mathrm{g} / \mathrm{mL})$, LPS $(1 \mu \mathrm{g} / \mathrm{mL})$ and unloaded MP were used as controls and subjected to the same experimental conditions.

\section{Mice immunization}

Eight weeks old female BALB/c mice, obtained from Harlan Interfauna Ibérica (Spain) and housed in specific pathogen free conditions, were used for immunization. The experiments were performed in compliance with the regulations of the Ethical Committee of the University of Navarre in line with the European legislation on animal experiments (86/609/EU).

Mice $(n=8)$ were immunized by intradermal route twice (days 0 and 14) with $10 \mu \mathrm{g}$ OVA in the following combinations (23): i) OVA in $50 \mu \mathrm{L}$ of PBS; ii) OVA and CpG sequences (10 $\mu \mathrm{g}$, the mean between the administered amount of $\mathrm{CpG}$ in PLGA 502 and $756 \mathrm{MP}$ ) physically mixed; iii) OVA loaded MP (OVA PLGA 502 and OVA PLGA 756); iv) CpG loaded MP (CpG PLGA 502 and CpG PLGA 756); v) OVA and CpG coencapsulated into MP (OVA CpG PLGA 502 and PLGA 756) and vi) OVA emulsified with complete Freund's adjuvant (CFA). PBS and CpG sequences in solution were administered as controls.

Blood samples were collected from the retroorbital plexus at day 49 after the first immunization. Samples were centrifuged and the resulting sera were pooled within each experimental group. Finally, the sera were diluted 1:10 in PBS and stored at $-80{ }^{\circ} \mathrm{C}$ until assayed by ELISA.

\section{Measurement of anti-OVA antibody levels in serum}

OVA-specific antibodies in the mouse serum were detected using an indirect ELISA (23). The experiment was carried out as follows: 96-well plates were coated with $1 \mu \mathrm{g}$ OVA in $100 \mu \mathrm{L}$ of carbonate-bicarbonate buffer $(\mathrm{pH}$ 9.6) and maintained overnight at $4{ }^{\circ} \mathrm{C}$. After being washed in PBS containing $0.05 \%$ Tween ${ }^{\circledR} 20$ (PBS-T20), test samples at different dilutions were added to wells and incubated during $4 \mathrm{~h}$ at $37{ }^{\circ} \mathrm{C}$. Then, unbound antibody was eliminated prior to the incubation with goat anti-mouse IgG1 or IgG2a horseradish peroxidase conjugate (diluted 1:1000 in PBS-T20; Nordic Immunology, The 
Netherlands). Following a $1 \mathrm{~h}$ incubation at $37^{\circ} \mathrm{C}$ and five washing steps, $100 \mu \mathrm{L}$ of chromogen and substrate solution (2, 2'-Azino-bis(3ethylbenzothiazoline-6-sulfonic acid and hydrogen peroxide) was added. After a final incubation of 30 minutes under agitation, the absorbance was measured at $405 \mathrm{~nm}$ by an iEMS Reader MF (Thermo Fisher Scientific, USA). Data were expressed as antibody titre, which is defined as the reciprocal of a serum dilution whose optical density was equal or above 0.2 than blank samples reading the absorbance at $405 \mathrm{~nm}$, starting from sample dilution 1:40.

\section{Cytokine assay}

On day 13 after first immunization (and before the second one), three mice in each group were sacrificed and spleens were removed and placed in supplemented RPMI 1640 medium under sterile conditions (30). Each spleen was smashed and cells within experimental groups were pooled in one flask. The cellular suspension was centrifuged for $10 \mathrm{~min}$ at $400 \times \mathrm{g}$, the supernatant discarded and the pellet washed twice with PBS. The splenocytes were suspended in lysis buffer $\left(\mathrm{NH}_{4} \mathrm{Cl} 0.15 \mathrm{M}, \mathrm{KHCO}_{3} 10 \mathrm{mM}\right.$, EDTA $\left.0.1 \mathrm{mM}\right)$ for $2 \mathrm{~min}$ to eliminate erythrocytes and refilled with RPMI 1640 to stop the reaction. This suspension was centrifuged $(5 \mathrm{~min}, 400 \times g$ ) and the pellet was resuspended in supplemented RPMI 1640 medium. The lymphocyte suspension was added to 96-well round bottom microtitre plates $\left(4 \times 10^{5}\right.$ cells/well) along with test antigen $(20,80$ and $160 \mu \mathrm{g} O V A / m l$ in a final volume of
$200 \mu \mathrm{L}$ per well). Negative (wells without antigen) and positive (wells containing $2 \mu \mathrm{g} / \mathrm{mL}$ concanavalin A) controls were used. The culture supernatants were collected for cytokine assay (IFN- $\gamma$ and IL-4; Pharmingen, BD Biosciences, USA) at $48 \mathrm{~h}$ after the stimulation and kept frozen at $-80{ }^{\circ} \mathrm{C}$ until testing.

\section{RESULTS}

\section{Characterization of OVA and/or CpG MP}

Table 1 summarizes the physico-chemical characteristics of PLGA 502 and 756 MP prepared by TROMS. All the batches displayed a uniform size distribution of around $1 \mu \mathrm{m}$, independently on the polymer and OVA and/or $\mathrm{CpG}$ content, as revealed laser diffraction. Whereas the zeta potential of OVA loaded MP was slightly positive (around $10 \mathrm{mV}$ ), CpG encapsulated or co-encapsulated MP exhibited a slight negative zeta potential. Irrespective of polymer, OVA and $\mathrm{CpG}$ loading efficiency were very high and increased when both were coencapsulated into the same microparticle formulations. So, OVA encapsulation efficiency increased from 20\% (OVA loaded MP) to $50 \%$ (OVA and $\mathrm{CpG}$ loaded MP), whereas $\mathrm{CpG}$ loading was always close to $80 \%$. From scanning electron microscopy studies (Figure 1), MP were found to be spherical, homogenous, without pores and with similar sizes than those obtained by laser diffractometry. Finally, the yield of the fabrication process was $70 \%$.

Table 1: Physicochemical characterization of MP containing OVA and/or CpG sequences and prepared using DOTAP to form a complex with the oligonucleotide. Data are expressed as mean \pm SD $(n=3)$.

\begin{tabular}{ccccccc}
\hline Polymer & Formulation & $\begin{array}{c}\mathrm{D}[4,3] \\
(\mu \mathrm{m})\end{array}$ & $\begin{array}{c}\text { Polydispersity } \\
(\mathrm{D}[4,3] / \mathrm{D}[3,2])\end{array}$ & $\begin{array}{c}\text { Zeta potential } \\
(\mathrm{mV})\end{array}$ & $\begin{array}{c}\text { OVA loading } \\
(\mu \mathrm{g} / \mathrm{mg} \mathrm{MP})\end{array}$ & $\begin{array}{c}\text { CpG loading } \\
(\mu \mathrm{g} / \mathrm{mg} \mathrm{MP})\end{array}$ \\
\hline \multirow{2}{*}{502} & OVA & $1.4 \pm 0.5$ & $1.2 \pm 0.1$ & $8.7 \pm 0.7$ & $22.8 \pm 1.0$ & - \\
& $\mathrm{CpG}$ & $1.0 \pm 0.2$ & $1.8 \pm 0.9$ & $-6.8 \pm 7.3$ & - & $45.0 \pm 3.3$ \\
& OVA CpG & $2.0 \pm 0.4$ & $3.6 \pm 0.4$ & $-12.4 \pm 6.10$ & $42.0 \pm 3.9$ & $45.2 \pm 6.5$ \\
\hline \multirow{2}{*}{756} & OVA & $0.9 \pm 0.5$ & $1.2 \pm 0.05$ & 10.6 & $14.9 \pm 3.3$ & - \\
& CpG & $1.4 \pm 0.8$ & $1.2 \pm 0.6$ & -3.0 & - & 50.3 \\
& OVA CpG & $1.7 \pm 0.5$ & $2.7 \pm 2.1$ & $-5.8 \pm 2.0$ & $62.5 \pm 8.7$ & $51.1 \pm 3.6$ \\
\hline
\end{tabular}




\section{In vitro release of OVA and $\mathrm{CpG}$ sequences} from the MP

Figure 2 show the release of OVA and $\mathrm{CpG}$ sequences from MP. The antigen release was higher for OVA containing MP (34\% and $16 \%$ for PLGA 756 and 502 MP, respectively, at day 38) than for antigen and oligonucleotide loaded MP (11\% and 3\% for PLGA 756 and 502 MP, respectively, at day 38) although, in all the cases, the release was slow throughout the experiment (Figure 2a). The rate was even slowed down in the presence of co-encapsulated $\mathrm{CpG}$ sequences. Also, the release of $\mathrm{CpG}$ oligonucleotides was sustained but slow until the end of the experiment (Figure 2b).

\section{OVA structural analysis and antigenicity and CpG integrity}

OVA containing MP were analysed by Coomassie Brilliant Blue staining and immunoblotting to discard any negative consequences on both structural integrity and antigenicity of OVA. After gel staining and immunoblotting, no differences were detected between microencapsulated OVA and the native protein in terms of structure or molecular weight (Figure 3 ). In consequence, the integrity and the antigenicity of OVA were not damaged along the preparation of any of the formulations. When studying these parameters in samples from release experiments, the structure and the antigenicity of the protein were unaltered in any of the formulations assessed (data not shown).

The results for the analysis of the $T_{m}$ values after incubation of the oligonucleotide extracted from the MP with its complementary strand and a fluorescent compound indicated that all the tested samples displayed identical values for the $\mathrm{T}_{\mathrm{m}}$ (within the limits of experimental error; $\pm 1{ }^{\circ} \mathrm{C}$ ) than the one observed for the oligonucleotide in PBS $\left(59.7^{\circ} \mathrm{C}\right)$ (Figure 4). CpG released from MP after 38 days was analysed in the same way in order to evaluate if the microacidic environment created by the degradation of the PLGA along the time could alter the integrity of the oligonucleotide released. Similarly, the melting temperature for released oligonucleotide was not altered throughout the time in any of the tested formulations (data not shown). In consequence, the integrity of the oligonucleotide was intact despite the degradation of the polymer, the organic solvent or the shearing forces used in the preparation of the MP.
Table 2: Sera antibody (IgG2a and IgG1 isotypes) response to OVA measured by indirect ELISA on sera from BALB/c mice intradermically immunized (days 0 and 14) with $10 \mu \mathrm{g}$ of OVA alone, combined with adjuvants (CpG sequences and CFA) or encapsulated in MP. The antibody titre is defined as the reciprocal of a serum dilution whose optical density was equal or above 0.2 than blank samples reading the absorbance at $405 \mathrm{~nm}$, starting from sample dilution 1:40.

\begin{tabular}{lccc}
\hline Treatment & $\begin{array}{c}\text { IgG2a } \\
\text { titre }\end{array}$ & $\begin{array}{c}\text { IgG1 } \\
\text { titre }\end{array}$ & IgG2a/IgG1 \\
\hline OVA & 0 & 9 & 0.00 \\
OVA + CpG & 9 & 10 & 0.90 \\
OVA PLGA 502 & 0 & 3 & 0.00 \\
OVA CpG PLGA 502 & 4 & 8 & 0.50 \\
OVA PLGA 756 & 7 & 13 & 0.54 \\
OVA CpG PLGA 756 & 0 & 5 & 0.00 \\
OVA + CFA & 11 & 19 & 0.57 \\
\hline
\end{tabular}
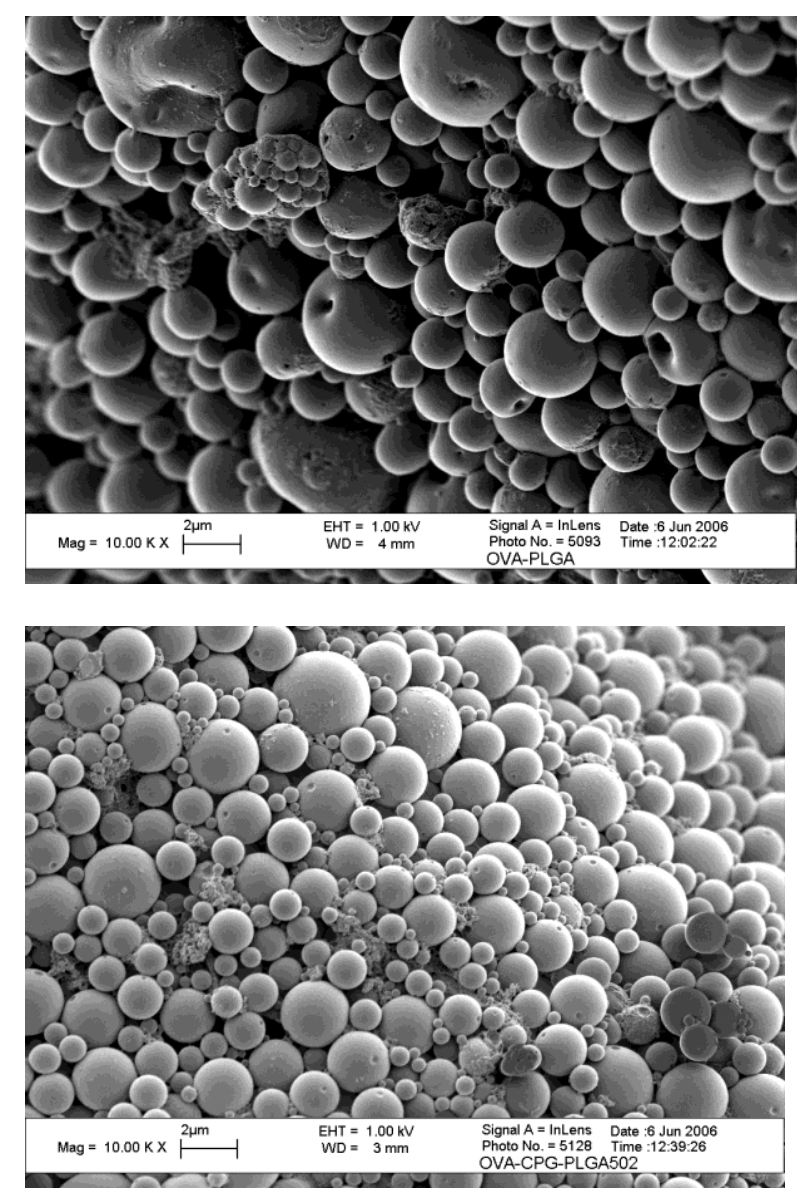

Figure 1. Scanning electron microscopy of lyophilized OVA (top) and OVACpG (bottom) loaded MP prepared by TROMS. 

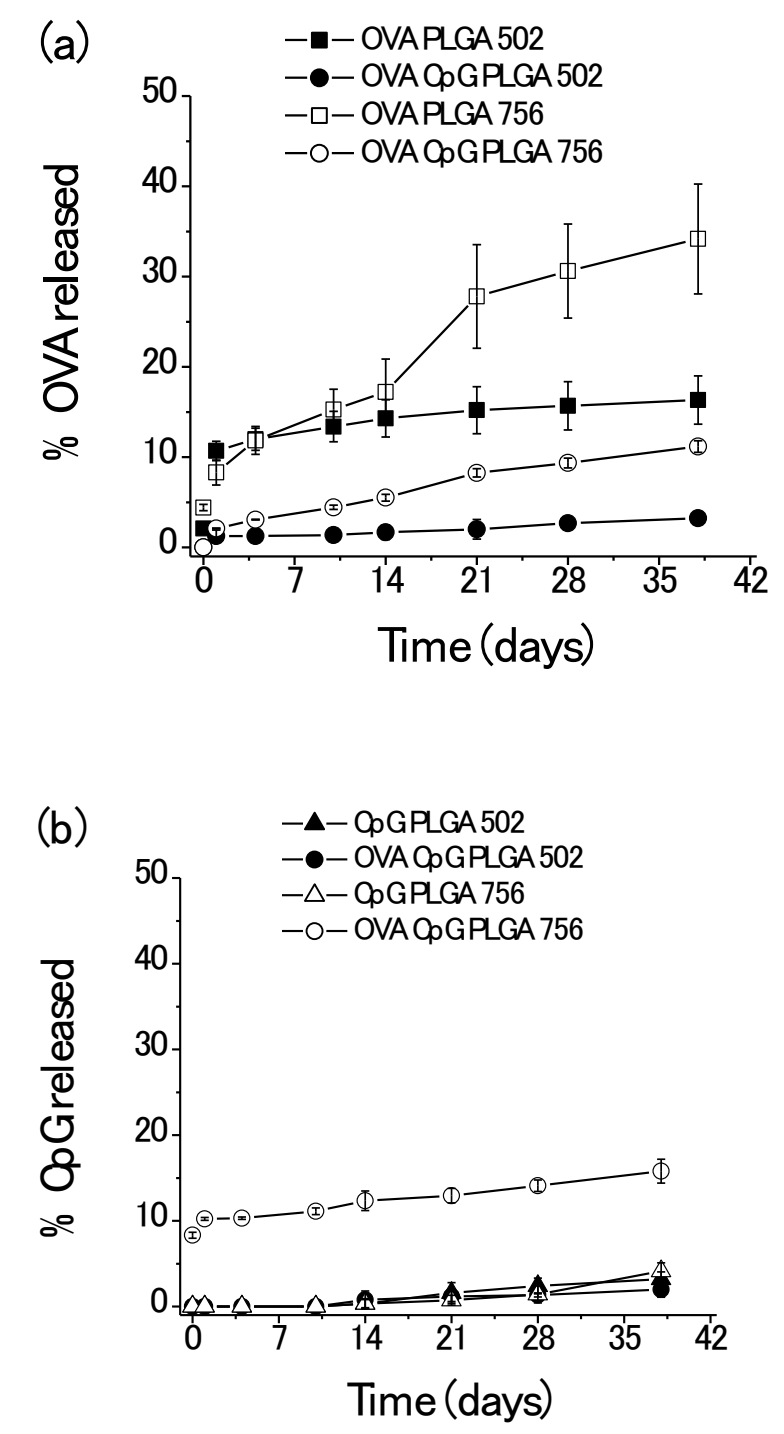

Figure 2. in vitro release of (a) OVA and (b) $\mathrm{CpG}$ sequences incubated under rotating agitation in PBS at $37^{\circ} \mathrm{C}$. Data are expressed as the cumulative release (\%) versus time (days). Data represent mean \pm SD of three independent experiments.

\section{Antibody response}

Table 2 shows the $\operatorname{IgG} 1$ and $\operatorname{IgG} 2 \mathrm{a}$ profile induced in experimental animals after double immunization with all the tested treatments. The encapsulation of the antigen into MP resulted in different outcomes depending on the polymer. For OVA PLGA 502, the immune profile was not modified $(\operatorname{IgG} 2 \mathrm{a} / \operatorname{IgG} 1=0.00)$ comparing with the free OVA ( $\operatorname{IgG} 2 \mathrm{a} / \mathrm{IgG} 1=0.00)$ but the antibody production (defined as the sum of $\operatorname{IgG} 1$ and IgG2a antibody titres) was decreased (from 9 titres for OVA in solution to 3 titres for OVA PLGA 502). In the case of OVA PLGA 756, the elicited immune profile was more balanced between the Th1 and Th2 responses

$(\mathrm{IgG} 2 \mathrm{a} / \mathrm{IgG} 1=0.54)$ achieving a most potent stimulation of the antibodies production (20 titres of $\operatorname{IgG1}$ and $\mathrm{IgG} 2 \mathrm{a}$ ) than the OVA control group.

Table 3: Cytokine production (IFN- $\gamma$ and IL-4) by splenocytes obtained from $\mathrm{BALB} / \mathrm{c}$ mice 13 days after intradermal immunization with $10 \mu \mathrm{g}$ of OVA alone, combined with adjuvants $(\mathrm{CpG}$ sequences and CFA) or encapsulated in MP. The resulting splenocytes suspensions were in vitro re-estimulated with $80 \mu \mathrm{g}$ OVA $/ \mathrm{mL}$ for $48 \mathrm{~h}$ to analyse IFN- $\gamma$ and IL-4 production (pg/mL).

\begin{tabular}{lccc}
\hline Treatment & $\begin{array}{c}\text { IFN- } \gamma \\
(\mathrm{pg} / \mathrm{mL})\end{array}$ & $\begin{array}{c}\text { IL-4 } \\
(\mathrm{pg} / \mathrm{mL})\end{array}$ & $\begin{array}{c}\text { IFN- } \\
\gamma / \mathrm{IL}-4\end{array}$ \\
\hline OVA & $422 \pm 57$ & $65 \pm 21$ & 6 \\
OVA + CpG & $3459 \pm 241$ & $111 \pm 76$ & 31 \\
$\begin{array}{l}\text { OVA PLGA } \\
\text { 502 }\end{array}$ & $2278 \pm 1641$ & $48 \pm 13$ & 47 \\
$\begin{array}{l}\text { OVA CpG } \\
\text { PLGA 502 }\end{array}$ & $1137 \pm 464$ & $8 \pm 11$ & 142 \\
OVA PLGA & $685 \pm 48$ & $12 \pm 1$ & 57 \\
756 & & & \\
OVA CpG & 0 & $39 \pm 36$ & 0 \\
PLGA 756 & & & \\
OVA + CFA & $3807 \pm 1474$ & $62 \pm 41$ & 61 \\
\hline
\end{tabular}

(a)

MW (kDa)

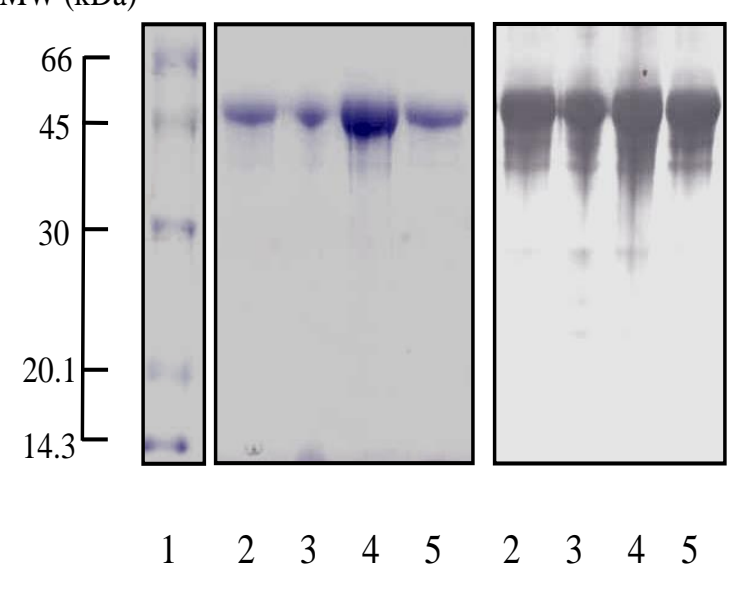

Figure 3: Study of the integrity of OVA after encapsulation in MP using TROMS. (a) SDS-PAGE stained for proteins (Coomasie Brilliant Blue R-250) and (b) Western-blot analysis with an anti-OVA immunoglobulin $\mathrm{G}$ and horseradish conjugated antiIgG from rabbit. Lane 1: molecular marker; 2: OVA PLGA 502; 3: OVA CpG PLGA 502; 4: OVA PLGA 756; 5: OVA CpG PLGA 756. Load was the equivalent to $10 \mu \mathrm{g}$ OVA/well. 
Whereas the administration of a solution of the antigen induced a strong Th2 response $(\mathrm{IgG} 2 \mathrm{a} / \mathrm{IgG} 1=0.00)$, the inclusion of $\mathrm{CpG}$ sequences resulted in a bias between $\operatorname{IgG} 2 \mathrm{a}$ and IgG1 antibodies production ( $\operatorname{IgG} 2 \mathrm{a} / \mathrm{IgG} 1=0.90$ ). Regarding the co-encapsulation, OVA $\mathrm{CpG}$ PLGA 502 displayed a balance between IgG1 and IgG2a responses but the potency and the specific antibody ratio (12 titres of $\operatorname{IgG} 1$ and $\operatorname{IgG} 2 \mathrm{a}$ and $\operatorname{IgG} 2 \mathrm{a} / \mathrm{IgG} 1=0.50)$ were inferior than the one obtained after the administration of $\mathrm{CpG}$ sequences and OVA in solution (19 titres of total IgG and IgG2a/IgG1=0.90). PLGA 756 containing both OVA and $\mathrm{CpG}$ sequences were not able to elicit a biased response $(\operatorname{IgG} 2 \mathrm{a} / \mathrm{IgG} 1=0.00)$ and the strength of the antibodies production was reduced (5 titres of IgG1 and IgG2a) in comparison with the physic mixture of both the antigen and the oligonucleotide.

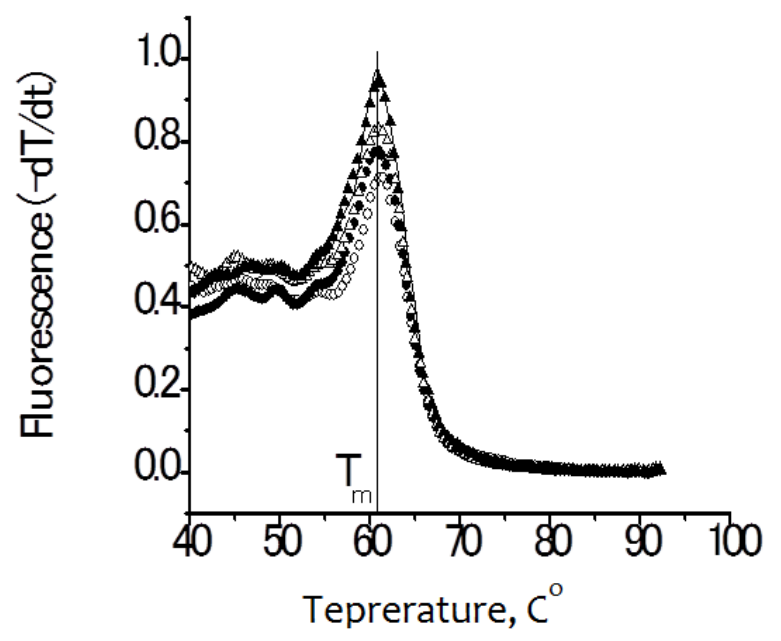

Figure 4: Fluorescence melting curve analysis of MP containing $\mathrm{CpG}$ sequences after extracting the oligonucleotide from the particles with $\mathrm{NaOH} 0.1 \mathrm{~N}$ overnight. Data are expressed plotting the negative derivative of fluorescence over temperature versus temperature. Free oligonucleotide (-) was subjected to the same experimental conditions and used as control. CpG PLGA 502 ( $\Delta$ ), OVA CpG PLGA 502 $(\bullet)$, CpG PLGA $756(\triangle)$ and OVA CpG PLGA 756 (०).

The expression of CD40 and CD86 and the production of IL-12 (a pro-Th1 cytokine) were measured in order to evaluate the effect of microencapsulation on the immunopotency of CpG. CD40 and CD86 surface markers, expressed as percent or mean fluorescent intensity (MFI) relative to non-stimulated DC, and IL-12p70 production are shown in Figure $5 \mathrm{a}$ and $5 \mathrm{~b}$, respectively. It can be observed that either free or associated to MP, CpG motifs induced similar level of DC maturation. No signs of DC activation were observed after cell incubation with unloaded PLGA MP, irrespective of polymer.

The encapsulation of OVA resulted in a less strong Th2 for PLGA 502 and in bias between Th1 and Th2 responses for PLGA 756 compared with the antigen in solution. Also, it can be observed that the addition of $\mathrm{CpG}$ sequences to the OVA loaded MP result in a benefit only for PLGA 502 (although not reaching to the potent immune response elicited by OVA and $\mathrm{CpG}$ in solution) whereas PLGA 756 containing CpG sequences were not able to improve the immunological balance obtained by OVA PLGA 756. Finally, the co-encapsulation of both molecules into particles did not provide any immunological benefit if comparing with the physic mixture.

\section{Cellular immune response}

The determination of IFN- $\gamma$ and IL-4 (Table 3) indicated which subset of Th cell population was predominant after one single shot by intradermal route with the treatments described above. The production of IFN- $\gamma$ displayed an enhancement, moderate for OVA PLGA $756(685 \pm 48 \mathrm{pg} / \mathrm{mL})$ and very strong for OVA PLGA $502(2278 \pm 1641$ $\mathrm{pg} / \mathrm{mL}$ ) in comparison with the result obtained from splenocytes treated with OVA in solution (422 pg/mL). Regarding the IL-4 level, these both treatments were able to diminish the production of this pro-Th2 cytokine $(12 \pm 1$ and $48 \pm 13 \mathrm{pg} / \mathrm{mL}$ for PLGA 756 and PLGA 502, respectively, versus $65 \pm 21 \mathrm{pg} / \mathrm{mL}$ for OVA in solution). Altogether, IFN- $\gamma / \mathrm{IL}-4$ ratio was more biased towards Th1 for OVA MP than for the antigen in solution (47 and 57 for OVA PLGA 502 and OVA PLGA 756, respectively, versus 6 for OVA).

As it was expected, the mixture of OVA and $\mathrm{CpG}$ sequences induced a high production of IFN$\gamma(3459 \pm 241 \mathrm{pg} / \mathrm{mL})$ accompanied with an increase in the production of IL-4 $(111 \pm 76$ $\mathrm{pg} / \mathrm{mL}$ ). The encapsulation of both molecules into MP was not able to achieve higher levels of IFN- $\gamma$ with none of the polymers $(1037 \pm 464$ and 0 $\mathrm{pg} / \mathrm{mL}$ for PLGA 502 and PLGA 756, respectively) but the IL-4 levels decreased 3-14 fold $(8 \pm 11$ and $35 \pm 36 \mathrm{pg} / \mathrm{mL}$ for PLGA 502 and PLGA 756, respectively) the production observed in OVA plus $\mathrm{CpG}$ sequences treated mice. Moreover, IFN- $\gamma / \mathrm{IL}-4$ ratio for OVA CpG PLGA 502 (IFN- $\gamma / \mathrm{IL}-4=142)$ was higher than the one observed with OVA and $\mathrm{CpG}$ sequences in 
solution (IFN- $\gamma / \mathrm{IL}-4=31$ ) or OVA loaded MP. Despite of the decrease of IL-4 production after immunization with OVA CpG PLGA 756, the lack of IFN- $\gamma$ production did not generate any modification in the Th1/Th2 immune balance.

Therefore, OVA loaded MP were able to generate more Th1 biased responses than the administration of the antigen in solution. However, the fact of co-encapsulation did not lead to an enhancement in the Th1 response but displayed a potent decrease of the pro-Th2 cytokine in comparison with the physical mixing of the antigen and the immunostimulatory sequences.

(a)

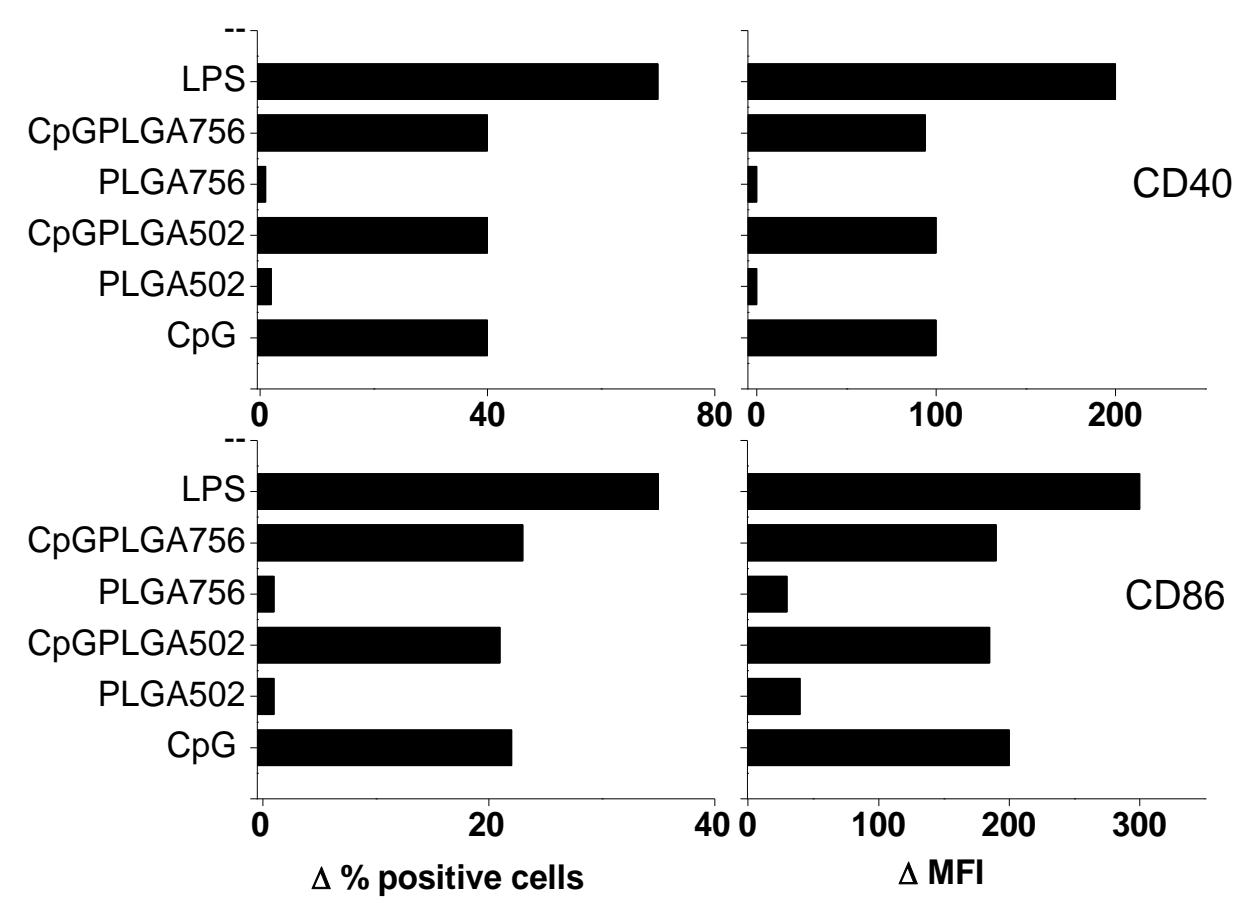

(b)

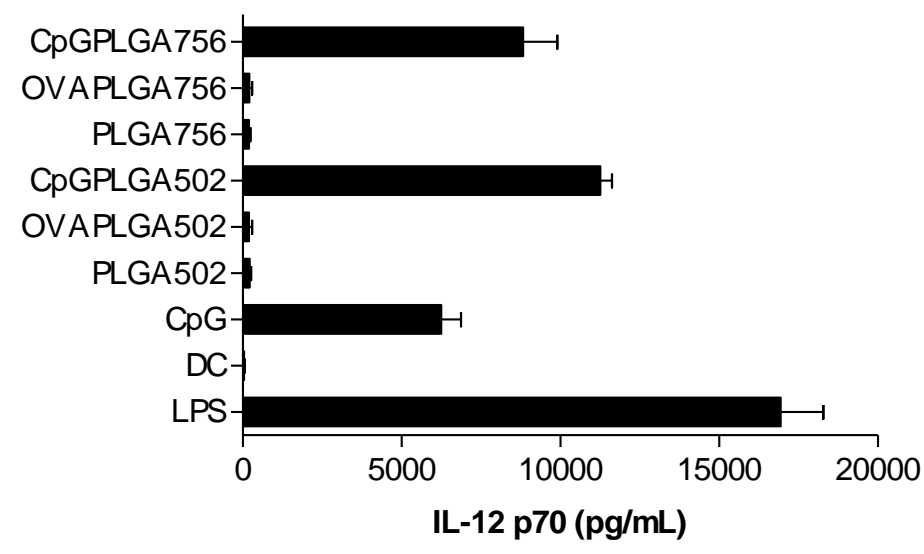

Figure 5: (a) Phenotypic maturation and (b) IL-12 production after $24 \mathrm{~h}$ incubation of BMDC with $2 \mu \mathrm{g} / \mathrm{mL}$ CpG, given either in solution or loaded into PLGA 502 or PLGA 756 MP. BMDC untreated (DC), receiving LPS (1 $\mu \mathrm{g} / \mathrm{mL})$, unloaded and OVA loaded PLGA 502 or PLGA 756 MP were included as controls. In (a) the bars perform the increase in percentage of CD40+ and CD80+ cells and Mean Fluorescence Intensity (MFI), calculated respect to control group (untreated DC). (a) Data of one experiment representative of the results from three independent experiments (b) Data represent mean \pm SD of two independent experiments. 


\section{DISCUSSION}

In this study we evaluated the immune response induced in $\mathrm{BALB} / \mathrm{c}$ mice after intradermal administration of $\mathrm{CpG}$ oligonucleotides (1826, B type) co-encapsulated with a model antigen (OVA) into $1 \mu \mathrm{m}$ DOTAP PLGA MP. Very high OVA and CpG loadings into non-charged PLGA 502 or PLGA 756 MP that prolonged their release over 38 days were achieved (see Table 1 and Figure 2) by using a previously described new double emulsion solvent evaporation method TROMS $(23,24)$.

The rational approach of the current study is that the $\mathrm{CpG}$ particulate delivery could enhance the adjuvanticity of $\mathrm{CpG}$ ODN by selective targeting to APC and enhanced interaction with their endosomal receptor TLR9 (31). In addition, their co-encapsulation with an antigen into the same particle guarantees their uptake by the same APC with the most specific immune activation. Several $\mathrm{CpG}$ and antigen delivery systems supporting this approach have been evaluated with success (32-36).

In this work, the optimal $\mathrm{CpG}$ encapsulation with prolonged release over 38 days was achieved by blending PLGA with the cationic lipid DOTAP into the organic phase during the process of microparticle preparation by TROMS (Table 1). $\mathrm{CpG}$ oligonucleotides were added into the inner aqueous phase. The negative influence of DOTAP in the OVA loading into MP (27\% encapsulation efficiency vs. $40 \%$ when MP were prepared in absence of DOTAP, data not shown) and the slightly positive zeta potential values of OVA DOTAP MP suggest a preferential disposition of the cationic lipid in the interfaces of the double emulsion, where amphiphilic OVA also tended to localise (Table 1). On the contrary, the return of OVA loading to normal levels and the negative zeta potential observed in formulations that coencapsulated the antigen with CpG ODN suggest the formation of hydrophobic ion-pair CpG:DOTAP complexes that are entrapped into the inner aqueous phase, allowing consistently high $\mathrm{CpG}$ encapsulation efficiencies and very slow and incomplete $\mathrm{CpG}$ release, irrespective of PLGA polymer.

In spite of $\mathrm{CpG}$ very slow and incomplete release, in vitro after $24 \mathrm{~h}$ incubation $\mathrm{CpG}$ loaded MP up-regulated CD40 and CD86 expression (Figure 5a) and activated BMDC for IL-12 production (Figure $5 \mathrm{~b}$ ) at the same level than free CpG ODN. Although a body of previous works found an enhancement in this cytokine secretion with the loading of $\mathrm{CpG}$ in delivery systems (37), others authors established more complex relationships between $\mathrm{CpG}$ physical presentation to cells and immunostimulatory properties. So, whereas soluble $\mathrm{CpG}$ trigger robust $\mathrm{IL}-12$ production on CD8 $\alpha+$ DC, CpG-DOTAP target in addition CD11c+ DC and non-DC cell types (38). The complexation of $\mathrm{CpG}$ with DOTAP also produced a modification in ODN intracellular trafficking prone to increase IFN- $\alpha$ production (39). Therefore, particle parameters such as size critically affected the immuno-stimulatory activities of CpG. In human blood cells, microencapsulated $\mathrm{CpG}$ preferentially target macrophages and increase TNF- $\alpha$ production whereas nanometric particles enhanced the uptake of $\mathrm{CpG}$ by $\mathrm{pDC}$ and the production of IFN- $\alpha$ (40). In vitro, in a DC-like cell line, it was observed that $\mathrm{CpG}$ bound to polystyrene nanoparticles stimulated the production of IL- 6 and IFN- $\alpha$ while those bound to MP produced only IL-6 (19). In another report, multimeric CpG ODN type A or CpG-B complexed with polymixin MP localize to endosomes and leads exclusively to IFN- $\alpha$ production from $\mathrm{pDC}$ whereas monomeric forms $\mathrm{CpG} \mathrm{B}$ ODN rapidly translocate to endosomes, losing capability to stimulate IFN- $\alpha$ production and gaining in APC maturation activity and production of inflammatory cytokines (41).

The localization of $\mathrm{CpG}$ ODN in the particles also played a prominent role in their adjuvanticity. So, the co-delivery of both $\mathrm{CpG}$ and the antigen MenB into the same PLGA particle produced stronger humoral immune responses that the co-administration of particles loading separately the antigen and $\mathrm{CpG}$ ODN (20). Furthermore, PLGA MP with adsorbed, but not encapsulated, CpG ODN mediated a significant increase in the percentage of IFN- $\gamma$ secreting CD8+ T cells. The low immunogenicity of CpG ODN co-encapsulated with the antigenic peptide SIINFEKL within PLGA MP was wellcorrelated with the low amounts of $\mathrm{CpG}$ released from the particles (21).

In contrast with the ability of microencapsulated $\mathrm{CpG}$ to stimulate $\mathrm{IL}-12$ production from DC in vitro (IL-12 is a potent Th1 promoting cytokine), the microparticulate delivery of CpG ODN with OVA induced a lower Th1 cell response (measured as IFN- $\gamma$ production) that either free $\mathrm{CpG}$ simply co-administered with the antigen or the OVA microencapsulated alone. The results were affected by the polymer type (Table 3). Whereas OVA or OVA and $\mathrm{CpG}$ entrapped into PLGA $502 \mathrm{MP}$ induced IFN- $\gamma$ 
production (Th1 response), the antigen encapsulated or co-encapsulated with $\mathrm{CpG}$ into PLGA 756 MP elicited negligible levels of this cytokine. Therefore, antibodies levels induced by MP containing OVA and CpG ODN were lower to that induced by the antigen and CpG ODN in solution, in agreement with the lower $\mathrm{T}$ cell responses observed (Table 2). Other authors have also reported that the particulate delivery of $\mathrm{CpG}$ tended to decrease the antibody response when compared with $\mathrm{CpG}$ simply co-administered with the antigen $(33,42)$. Whereas $\mathrm{CpG}$ given in saline are accessible to B cells directly (43), CpG ODN needs to be released from MP to stimulate nonphagocytic B cells. In the current study, the fractions of $\mathrm{CpG}$ released from MP could be suboptimal for B cell stimulation as a consequence of the very slow release observed.

It is known that polymers can modulate the type of immune response addressed to the carried antigens. In this study, whereas OVA alone or OVA loaded into PLGA 502 MP triggered IgG1 antibody response, OVA microencapsulated into PLGA 756 displayed higher antibody titres, increased production of $\mathrm{IgG} 2 \mathrm{a}$ antibodies (Table 2) and higher IFN- $\gamma / \mathrm{IL}-4$ ratio (Table 3). Furthermore, the antibodies production was enhanced as a consequence of the $\mathrm{CpG}$ coencapsulation and it was observed a shift of isotype profile only in mice immunized with $\mathrm{CpG}$ loaded PLGA 502. OVA CpG 756 elicited only low IgG1 (Table 2) and IFN- $\gamma$ production (Table $3)$. Both, the highest antibodies production and IFN- $\gamma / \mathrm{IL}-4$ ratio, were observed in mice immunized with PLGA 502 MP loading OVA and CpG. In agreement with this finding, only OVAsensitized mice treated with MP co-encapsulating OVA plus $\mathrm{CpG}$ were totally protected from death by anaphylaxis (44).

Overall, this work introduces that polymer affects the adjuvanticity of microencapsulated CpG ODN and antigen. However, the differences between the immune response elicited by PLGA 502 and PLGA 756 cannot be ascribed to any significant differences either in the amount and rate of antigen and $\mathrm{CpG}$ released from MP or in vitro stimulatory effect in BMDC. The release of antigen and $\mathrm{CpG}$ should be analysed after phagocytic uptake of MP by APC at the intracellular level. Furthermore, although in vitro free or encapsulated $\mathrm{CpG}$ similarly stimulated $\mathrm{DC}$, in vivo the polymer could also modulate the complement activation or inflammation produced by the particles at the site of administration, keys in their immunoadjuvant properties (3). In this context, further analysis using different molecular weight of PLGA and using different polymers should be performed in order to conclude a general effect of the polymeric MP on the in vivo activity.

Polymeric particles perform an excellent and extremely versatile platform for designing vaccine adjuvants with the required characteristics, allowing fine tuning over the variables that are important in optimizing an effective vaccine delivery system. However, there are big gaps to fill in the influence of particles characteristics in the out coming immune response to fully exploit the potential of particulates as vaccine adjuvants. Multiple papers described the goodness and great versatility of PLGA microspheres as adjuvants for vaccination. However, only PLGA MP with adsorbed HIV-1 DNA underwent Phase I clinical testing in the USA (45). In the lead, either CpG, monophosphoryl lipid A and imiquimod (TLR agonists) or other particulate adjuvants as Alum or the emulsions MF59 ${ }^{\circledR}$ are currently approved for use in human vaccines. In general, particles enhance antibodies production. However, they produced Th0 $\left(\mathrm{MF}^{\circledR} 9^{\circledR}\right)$ or poor Th2 (Alum) skewed immune responses (46). On the contrary, the triggering of TLR tends to induce a strong Th1-biased helper T-cell response and cytotoxic $\mathrm{T}$ lymphocyte activation. In order to find their niche in this scenario, MP should set their advantages and particularities, if any, in terms of both efficacy and security through their systematic comparison with currently approved adjuvants, especially those particulates in nature (Alum and MF59 ${ }^{\circledR}$ ).

\section{ACKNOWLEDGEMENTS}

The authors would like to thank Maite Hidalgo and Rocío Martínez for excellent technical assistance. BSR had a grant from Asociación de Amigos de la Universidad de Navarra and the work was financially supported by "Ministerio de Educación y Ciencia" (SAF 2004-07150) and Caja de Ahorros de Navarra (Programa Tú eliges: Tú decides). Besides, the authors report no declarations of interest.

\section{REFERENCES}

1. Singh M, Chakrapani A, O'Hagan D. Nanoparticles and microparticles as vaccinedelivery systems. Expert Rev Vaccines, 2007; 6(5):797-808.

2. Sharp FA, Ruane D, Claass B, Creagh E, Harris J, Malyala $\mathrm{P}$, et al. Uptake of particulate vaccine 
adjuvants by dendritic cells activates the NALP3 inflammasome. Proc Natl Acad Sci U S A, 2009; 106(3):870-875.

3. De Gregorio E, D'Oro U, Wack A. Immunology of TLR-independent vaccine adjuvants. Curr Opin Immunol, 2009; 21(3):339-345.

4. Chen M, Wang H, Chen W, Meng G. Regulation of adaptive immunity by the NLRP3 inflammasome. Int Immunopharmacol, 2010.

5. Harris J, Sharp FA, Lavelle EC. The role of inflammasomes in the immunostimulatory effects of particulate vaccine adjuvants. Eur J Immunol, 2010; 40(3):634-638.

6. Iwasaki A, Medzhitov R. Toll-like receptor control of the adaptive immune responses. Nat Immunol, 2004; 5(10):987-995.

7. Manicassamy S, Pulendran B. Modulation of adaptive immunity with Toll-like receptors. Semin Immunol, 2009; 21(4):185-193.

8. Duthie MS, Windish HP, Fox CB, Reed SG. Use of defined TLR ligands as adjuvants within human vaccines. Immunol Rev, 2011; 239(1):178-196.

9. Israeli E, Agmon-Levin N, Blank M, Shoenfeld Y. Adjuvants and autoimmunity. Lupus, 2009; 18(13):1217-1225.

10. Krieg AM, Vollmer J. Toll-like receptors 7, 8, and 9: linking innate immunity to autoimmunity. Immunol Rev, 2007; 220:251-269.

11. Guy B. The perfect mix: recent progress in adjuvant research. Nat Rev Microbiol, 2007; 5(7):505-517.

12. Demento SL, Eisenbarth SC, Foellmer HG, Platt C, Caplan MJ, Mark Saltzman W, et al. Inflammasome-activating nanoparticles as modular systems for optimizing vaccine efficacy. Vaccine, 2009; 27(23):3013-3021.

13. Coffman RL, Sher A, Seder RA. Vaccine adjuvants: putting innate immunity to work. Immunity, 2010; 33(4):492-503.

14. Didierlaurent AM, Morel S, Lockman L, Giannini $\mathrm{SL}$, Bisteau M, Carlsen $\mathrm{H}$, et al. AS04, an aluminum salt- and TLR4 agonist-based adjuvant system, induces a transient localized innate immune response leading to enhanced adaptive immunity. J Immunol, 2009; 183(10):6186-6197.

15. Kanchan V, Panda AK. Interactions of antigenloaded polylactide particles with macrophages and their correlation with the immune response. Biomaterials, 2007; 28(35):5344-5357.

16. Oyewumi MO, Kumar A, Cui Z. Nanomicroparticles as immune adjuvants: correlating particle sizes and the resultant immune responses. Expert Rev Vaccines, 2010; 9(9):1095-1107.

17. Kanchan V, Katare YK, Panda AK. Memory antibody response from antigen loaded polymer particles and the effect of antigen release kinetics. Biomaterials, 2009; 30(27):4763-4776.

18. Katare YK, Muthukumaran T, Panda AK. Influence of particle size, antigen load, dose and additional adjuvant on the immune response from antigen loaded PLA microparticles. Int J Pharm, 2005; 301(1-2):149-160.

19. Chen HC, Sun B, Tran KK, Shen H. Effects of particle size on toll-like receptor 9-mediated cytokine profiles. Biomaterials, 2011; 32(6):17311737.

20. Malyala P, Chesko J, Ugozzoli M, Goodsell A, Zhou F, Vajdy M, et al. The potency of the adjuvant, CpG oligos, is enhanced by encapsulation in PLG microparticles. J Pharm Sci, 2008; 97(3):1155-1164.

21. Fischer S, Schlosser E, Mueller M, Csaba N, Merkle HP, Groettrup M, et al. Concomitant delivery of a CTL-restricted peptide antigen and CpG ODN by PLGA microparticles induces cellular immune response. J Drug Target, 2009; 17(8):652-661.

22. Hutchinson FG, Furr BJ. Biodegradable polymers for the sustained release of peptides. Biochem Soc Trans, 1985; 13(2):520-523.

23. San Román B, Irache JM, Gomez S, Tsapis N, Gamazo C, Espuelas MS. Co-encapsulation of an antigen and $\mathrm{CpG}$ oligonucleotides into PLGA microparticles by TROMS technology. Eur J Pharm Biopharm, 2008; 70(1):98-108.

24. del Barrio GG, Novo FJ, Irache JM. Loading of plasmid DNA into PLGA microparticles using TROMS (Total Recirculation One-Machine System): evaluation of its integrity and controlled release properties. J Control Release, 2003; 86(1):123-130.

25. Estevan M, Gamazo C, Grilló MJ, Del Barrio GG, Blasco JM, Irache JM. Experiments on a sub-unit vaccine encapsulated in microparticles and its efficacy against Brucella melitensis in mice. Vaccine, 2006; 24(19):4179-4187.

26. Laemmli UK. Cleavage of structural proteins during the assembly of the head of bacteriophage T4. Nature, 1970; 227(5259):680-685.

27. Fairbanks G, Steck TL, Wallach DF. Electrophoretic analysis of the major polypeptides of the human erythrocyte membrane. Biochemistry, 1971; 10(13):2606-2617.

28. Gamazo C, Winter AJ, Moriyón I, Riezu-Boj JI, Blasco JM, Díaz R. Comparative analyses of proteins extracted by hot saline or released spontaneously into outer membrane blebs from field strains of Brucella ovis and Brucella melitensis. Infect Immun, 1989; 57(5):1419-1426.

29. Arnedo A, Espuelas S, Irache JM. Albumin nanoparticles as carriers for a phosphodiester oligonucleotide. Int J Pharm, 2002; 244(1-2):5972.

30. Sarobe P, Lasarte JJ, Zabaleta A, Arribillaga L, Arina A, Melero I, et al. Hepatitis C virus structural proteins impair dendritic cell maturation and inhibit in vivo induction of cellular immune responses. J Virol, 2003; 77(20):10862-10871.

31. Krishnamachari Y, Salem AK. Innovative strategies for co-delivering antigens and $\mathrm{CpG}$ 
oligonucleotides. Adv Drug Deliv Rev, 2009; 61(3):205-217.

32. Gursel I, Gursel M, Ishii KJ, Klinman DM. Sterically stabilized cationic liposomes improve the uptake and immunostimulatory activity of CpG oligonucleotides. J Immunol, 2001; 167(6):3324-3328.

33. Diwan M, Tafaghodi M, Samuel J. Enhancement of immune responses by co-delivery of a $\mathrm{CpG}$ oligodeoxynucleotide and tetanus toxoid in biodegradable nanospheres. J Controlled Release, 2002; 85(1-3):247-262.

34. Xie H, Gursel I, Ivins BE, Singh M, O'Hagan DT, Ulmer JB, et al. CpG oligodeoxynucleotides adsorbed onto polylactide-co-glycolide microparticles improve the immunogenicity and protective activity of the licensed anthrax vaccine. Infect Immun, 2005; 73(2):828-833.

35. Zhang XQ, Dahle CE, Weiner GJ, Salem AK. A comparative study of the antigen-specific immune response induced by co-delivery of $\mathrm{CpG}$ ODN and antigen using fusion molecules or biodegradable microparticles. J Pharm Sci, 2007; 96(12):32833292.

36. Martínez Gómez JM, Fischer S, Csaba N, Kundig TM, Merkle HP, Gander B, et al. A protective allergy vaccine based on $\mathrm{CpG}$ - and protaminecontaining PLGA microparticles. Pharm Res, 2007; 24(10):1927-1935.

37. Kwon YJ, Standley SM, Goh SL, Frechet JM. Enhanced antigen presentation and immunostimulation of dendritic cells using aciddegradable cationic nanoparticles. J Control Release, 2005; 105(3):199-212.

38. Hou B, Reizis B, DeFranco AL. Toll-like receptors activate innate and adaptive immunity by using dendritic cell-intrinsic and -extrinsic mechanisms. Immunity, 2008; 29(2):272-282.
39. Honda K, Ohba Y, Yanai H, Negishi H, Mizutani T, Takaoka A, et al. Spatiotemporal regulation of MyD88-IRF-7 signalling for robust type-I interferon induction. Nature, 2005; 434(7036):1035-1040.

40. Rettig L, Haen SP, Bittermann AG, von Boehmer L, Curioni A, Kramer SD, et al. Particle size and activation threshold: a new dimension of danger signaling. Blood, 2010; 115(22):4533-4541.

41. Guiducci C, Ott G, Chan JH, Damon E, Calacsan $\mathrm{C}$, Matray $\mathrm{T}$, et al. Properties regulating the nature of the plasmacytoid dendritic cell response to Tolllike receptor 9 activation. J Exp Med, 2006; 203(8):1999-2008.

42. Tafaghodi M, Sajadi Tabassi SA, Jaafari MR. Induction of systemic and mucosal immune responses by intranasal administration of alginate microspheres encapsulated with tetanus toxoid and CpG-ODN. Int J Pharm, 2006; 319(1-2):37-43.

43. Takeshita F, Leifer CA, Gursel I, Ishii KJ, Takeshita S, Gursel M, et al. Cutting edge: Role of Toll-like receptor 9 in $\mathrm{CpG}$ DNA-induced activation of human cells. J Immunol, 2001; 167(7):3555-3558.

44. San Román B, Irache JM, Gómez S, Gamazo C, Espuelas S. Co-delivery of ovalbumin and $\mathrm{CpG}$ motifs into microparticles protected sensitized mice from anaphylaxis. Int Arch Allergy Immunol, 2009; 149(2):111-118.

45. Reed SG, Bertholet S, Coler RN, Friede M. New horizons in adjuvants for vaccine development. Trends Immunol, 2009; 30(1):23-32.

46. Tritto E, Mosca F, De Gregorio E. Mechanism of action of licensed vaccine adjuvants. Vaccine, 2009; 27(25-26):3331-3334. 